\title{
Edulcorante na Água de Consumo e Efeitos Sobre o Desempenho e o Desenvolvimento da Mucosa Intestinal de Leitões Submetidos ao Desmame Precoce Segregado
}

\section{Caio Abércio da Silva ${ }^{1}$, Fábio Luis Rocha ${ }^{2}$, Glauber Souza Machado ${ }^{2}$, Rodolfo Nascimento Kronka $^{3}$, Maria Cristina Thomaz ${ }^{3}$, Werner Okano', Nilva Nicolao Fonseca ${ }^{1}$, João Waine Pinheiro' ${ }^{1}$, Lizete Cabrera ${ }^{1}$}

\begin{abstract}
RESUMO - Um experimento foi realizado com o objetivo de verificar os efeitos da indução do consumo de água com edulcorante, na fase de berçário (10 aos 30 dias de idade), sobre o desempenho de 270 leitões (machos e fêmeas) submetidos ao desmame precoce segregado e os efeitos residuais nas fases de pré-creche ( 30 aos 45 dias) e de creche ( 45 aos 62 dias de idade). Três tratamentos com dois sexos e três repetições (fatorial 3 x 2) foram utilizados dos 10 aos 30 dias de idade dos leitões, sendo: T1- água sem edulcorante, T2 - água com edulcorante e T3 - água com e sem edulcorante oferecidos simultaneamente em bebedouros distintos. Foram avaliados o ganho diário de peso, o consumo diário de ração e a conversão alimentar. O consumo diário de água somente foi medido na fase de berçário. A incidência de diarréia foi observada até o 10 o dia após o desmame. Aos 22 dias de idade, seis leitões por tratamento foram sacrificados para avaliação da altura das vilosidades e profundidade das criptas da mucosa do duodeno e jejuno. Não foram observadas diferenças para as variáveis estudadas, exceto para o ganho diário de peso e consumo diário de ração nas fases compreendidas entre 30 e 45 dias e 45 e 62 dias e para o ganho diário de peso entre 10 e 62 dias, a favor das fêmeas. O uso de edulcorante na água não influenciou o consumo de água, o desempenho dos leitões e a qualidade da mucosa intestinal.
\end{abstract}

Palavras-chave: água, edulcorante, leitões, suínos

\section{Sweetener in the Drinking Water and Effects on Performance and on the Development of Intestinal Mucosa for Piglets Subject to Segregated Early Weaned}

\begin{abstract}
An experiment was conducted with the objective to evaluate the effects of the induction of the drinking water with sweetener consumption in the nursery phase $\left(10^{\text {th }}\right.$ to $30^{\text {th }}$ day of age), on the performance of 270 piglets (male and females) submitted to segregated early weaned and its residual effects on their pre nursery ( $30^{\text {th }}$ to $45^{\text {th }}$ day) and nursery phases $\left(45^{\text {th }}\right.$ to $62^{\text {nd }}$ day) were evaluated. A completely randomized design in a 3 x 2 factorial arrangement with three treatments with two sexes and three replications were used from 10 to 30 days of age of the piglets. The treatment were: T1- drinking water without sweetener; T2 - drinking water with sweetener and T3 - drinking water with and without sweetener simultaneously offered. Average daily gain, daily feed intake and feed: gain was recorded at $30^{\text {th }}, 45^{\text {th }}$ and $62^{\text {nd }}$ days. Daily drinking water consumption was recorded only from the $10^{\text {th }}$ to $30^{\text {th }}$ day. Six piglets per treatment were slaughtered at the $22^{\text {nd }}$ day and a medium part of the duodenum and jejunum samples were collected to measure villi height and crypt depth. Diarrhea incidence was observed up to 10 days after weaning. It was not observed differences for the studied variables, except for average daily gain and daily feed intake from $30^{\text {th }}$ to $45^{\text {th }}$ and $45^{\text {th }}$ to $62^{\text {nd }}$ days phases and for average daily gain from $10^{\text {th }}$ to $62^{\text {nd }}$ days that favored the female piglets. The use of drinking water with sweetener did not affect the water consumption, the piglet performance and the mucosa intestinal quality.
\end{abstract}

Key Words: piglets, sweetener, swine, water

\section{Introdução}

A redução da idade do desmame constitui-se na forma mais efetiva de aumento do número de ciclos reprodutivos anuais (COLE et al., 1975; FREITAS et al., 1997). Nesse sentido, o desmame precoce segregado (DPS) apresenta-se como nova tecnologia para a otimização da eficiência reprodutiva e produtiva dos plantéis, pelo aumento do número de partos por porca por ano e pela redução dos efeitos negativos decorrentes da ação de certas doenças que acometem os rebanhos (PASSOS, 1997). Esta tendência de redução do número de dias da lactação, porém, tem tornado os leitões potenciais vítimas de choques fisiológicos, com mudanças na estrutura da mucosa intestinal e piora no desempenho subseqüente (MORES, 1993).

No desmame ocorrem alterações na histologia e morfologia intestinal, além de comprometimento

\footnotetext{
1 Universidade Estadual de Londrina. Departamento de Zootecnia. CEP 86020-990, Londrina - PR. E-mail: casilva@npd.uel.br

2 Seghers Hybrid do Brasil Agropecuária Ltda., Patos de Minas - MG. E.mail: glauber@larnet.com.br

3 Universidade Estadual Paulista, Jaboticabal - SP. E.mail: thomaz@fcav.unesp.br
} 
aparente da digestão e absorção, entretanto, por intermédio de processos normais de maturação e produção enzimática em resposta aos componentes da dieta, rapidamente estas estruturas se recuperam. A quantidade e a composição da dieta antes e após o desmame induz respostas digestivas específicas (PEKAS, 1991).

O baixo consumo de ração é apontado como um fator que contribui para a abrupta redução do comprimento das vilosidades, indicando que o fornecimento de dietas com elevado valor nutricional e alta digestibilidade, portanto, estimuladoras do consumo, apresentam-se como um recurso efetivo para minimizar os efeitos deletérios do pós-desmame (CERA et al., 1988).

Outras teorias têm mostrado que uma relação entre o consumo no período pós-desmame e a integridade morfológica da parede intestinal demonstra o efeito estimulante do alimento ingerido sobre a maturação do epitélio intestinal (KELLY et al., 1991; MAKKING et al, 1994). Consumo elevado no pósdesmame conduz à maior produção enzimática e melhora a digestão, resultando em maior consumo e aumento no ganho de peso (BERTO, 1993).

No estudo dos diferentes fatores que afetam o consumo de ração dos leitões recém-desmamados, grande atenção tem sido dirigida aos efeitos da água, pela relação positiva da sua ingestão com o consumo de ração, seja adicionando-a nas rações (DEPREZ et al., 1987; BERTO, 1993; HEIMIG, 1996; FREITAS et al., 1997), ou estimulando seu consumo nos bebedouros, com o uso de adoçantes (McDONALD et al., 1987; STOCKILL, 1990; e MAENZ et al., 1993).

É importante registrar que, em geral, leitões jovens necessitam mais água por quilograma de peso vivo que animais mais velhos, fato que por si só justifica a importância da água neste período. Atribui-se esta ocorrência à maior área de superfície corporal e dos pulmões, em relação ao peso, e à tendência destes animais apresentarem urina mais diluída (WHITTEMORE, 1998).

MAENZ et al. (1993), estudando os efeitos do consumo de água no desempenho de suínos desmamados às 4 semanas, verificaram que adoçantes na água não afetaram significativamente o consumo de alimentos e de água pelos animais, entretanto, houve correlação entre o consumo cumulativo de água e o consumo cumulativo de alimento, estando o consumo de alimento relacionado com o ganho de peso.

McDONALD et al. (1987) verificaram que a adição de sacarose na água atuava como palatabilizante, conferindo um sabor adocicado que atendia a preferência dos leitões, favorecendo seu maior consumo. STOCKILL (1990) observou que a adição de edulcorante na água proporcionou aumento de duas a três vezes no seu consumo nos três primeiros dias após o desmame, havendo, conseqüentemente, aumento na ingestão de ração e melhora no desempenho dos leitões.

As controvérsias sobre a utilização de adoçantes na água são justificadas pelos vários fatores que regulam seu consumo. Com base em alguns resultados positivos determinados pela indução do consumo de água e considerando os desafios a que estão sujeitos os leitões submetidos ao desmame precoce segregado, este estudo foi conduzido com o objetivo de verificar a eficiência da adição de edulcorante na água sobre o desempenho dos leitões até o final da fase de creche.

\section{Material e Métodos}

Os experimentos foram conduzidos utilizando-se as seguintes instalações: berçário (10 aos 30 dias de idade), pré-creche (30 aos 45 dias) e creche (45 aos 62 dias). Foram utilizadas 18 baias em cada fase, com 15 animais/baia. As áreas das baias das fases de berçário, pré-creche e creche foram, respectivamente, de 2,24; 2,40; e $2,75 \mathrm{~m}^{2}$. No berçário, a temperatura foi mantida entre 29 e $31^{\circ} \mathrm{C}$.

Foram utilizados 270 leitões híbridos (135 machos e 135 fêmeas), desmamados aos 10 dias de idade, com peso médio inicial de $3,048 \mathrm{~kg}$. Os animais receberam rações comerciais, cujos níveis nutricionais foram específicos para cada fase (Tabela 1).

Os tratamentos foram orientados na fase de berçário correspondendo a: T1-água sem edulcorante; T2 - água com edulcorante; e T3- água com edulcorante e sem edulcorante, oferecidas em bebedouros distintos. Para os tratamentos com edulcorante, foi utilizado o produto SUCRAM 200 (sacarina sódica) na dosagem de 200 g/1000 litros de água. Nas fases seguintes, os grupos experimentais receberam todos o mesmo manejo, ou seja, água sem edulcorante e ração específica para a fase. Foram avaliadas em cada fase as médias do ganho diário de peso, do consumo diário de ração e da conversão alimentar. $\mathrm{O}$ consumo médio diário de água por animal somente foi avaliado na fase de berçário.

Para a avaliação da incidência de diarréia, todos os leitões foram acompanhados durante os 10 primeiros dias da fase de berçário, sendo realizadas duas observações por dia (1 hora de manhã e 1 hora à tarde). Foi 
1772 Rev. bras. zootec.

Tabela 1 - Valores nutricionais das rações experimentais pré-inicial 1 (10-25 dias), pré-inicial 2 (26-35 dias), inicial 1 (36-46 dias) e inicial 2 (47-62 dias)

Table 1 - Nutritional values of the experimental diets pre-initial 1 (10-25 days), pre initial 2 (26-35 days), initial 1 (36-45 days) and initial 2 (47-62 days)

\begin{tabular}{|c|c|c|c|c|}
\hline \multirow[t]{3}{*}{$\begin{array}{l}\text { Nutrientes } \\
\text { Nutrients }\end{array}$} & \multicolumn{4}{|c|}{$\begin{array}{l}\text { Rações } \\
\text { Diets }\end{array}$} \\
\hline & Pré-inicial 1 & Pré-inicial 2 & Inicial 1 & Inicial 2 \\
\hline & Pre-initial 1 & Pre-initial 2 & Initial 1 & Initial 2 \\
\hline $\begin{array}{l}\text { Energia digestível }(\mathrm{kcal} / \mathrm{kg}) \\
\text { Digestible energy }(\mathrm{kcal} / \mathrm{kg})\end{array}$ & 3651 & 3502 & 3476 & 3409 \\
\hline $\begin{array}{l}\text { Proteína }(\%) \\
\text { Pol }\end{array}$ & 20,71 & 20,00 & 19,61 & 20,91 \\
\hline $\begin{array}{l}\text { Protein }(\%) \\
\text { Gordura }(\%) \\
\text { Crude fat }(\%)\end{array}$ & 7,96 & 6,22 & 6,66 & 4,74 \\
\hline $\begin{array}{l}\text { Fibra }(\%) \\
\text { Fiber }(\%)\end{array}$ & 1,97 & 2,53 & 2,95 & 3,55 \\
\hline $\begin{array}{l}\text { Mineral (\%) } \\
\text { Ash (\%) }\end{array}$ & 4,89 & 4,82 & 5,03 & 5,23 \\
\hline $\begin{array}{l}\text { Cálcio(\%) } \\
\text { Calcium (\%) }\end{array}$ & 0,65 & 0,62 & 0,72 & 0,71 \\
\hline $\begin{array}{l}\text { Fósforo total }(\%) \\
\text { Total phosphorus } t(\%)\end{array}$ & 0,72 & 0,61 & 0,61 & 0,63 \\
\hline $\begin{array}{l}\text { Metionina (\%) } \\
\text { Methionine (\%) }\end{array}$ & 0,51 & 0,52 & 0,45 & 0,38 \\
\hline $\begin{array}{l}\text { Lisina (\%) } \\
\text { Lysine (\%) }\end{array}$ & 1,50 & 1,50 & 1,37 & 1,20 \\
\hline $\begin{array}{l}\text { Triptofano }(\%) \\
\text { Tryptophan }(\%)\end{array}$ & 0,23 & 0,23 & 0,23 & 0,26 \\
\hline $\begin{array}{l}\text { Treonina (\%) } \\
\text { Threonine (\%) }\end{array}$ & 0,92 & 0,92 & 0,86 & 0,78 \\
\hline
\end{tabular}

considerado o lote com diarréia aquele que apresentou $20 \%$ ou mais dos animais com fezes amolecidas a líquidas e/ou com mudança de coloração. A classificação do grau de acometimento do lote, por sua vez, obedeceu à seguinte ordem: $0=$ sem diarréia (0 dias); 1 = pouca diarréia (1-3 dias); e 2 = muita diarréia (4ou mais dias) (MADEC et al., 1989; VIEIRA et al., 1989).

Para avaliação histológica da mucosa do duodeno e jejuno, foram sacrificados 18 leitões aos 22 dias de idade, escolhidos ao acaso, sendo um animal de cada repetição. Amostras de aproximadamente $1 \mathrm{~cm}$ da porção média do duodeno e jejuno de cada animal foram coletadas e, posteriormente, abertas pela borda mesentérica e estendidas pela serosa. A seguir, foram fixadas em solução de Bouin por 24 horas. Após, as amostras foram lavadas em álcool etílico a $70 \mathrm{GL}$ e desidratadas para a realização dos cortes longitudinais no micrótomo (30 cortes semi-seriados com $5 \mathrm{~mm}$ de espessura). Os cortes, posteriormente, foram corados pela hematoxilina Hans-eosina e analisados morfológica e morfometricamente em um analizador de imagens KONTRON ELEKTRONIK (Video Plan), aumento de 230 vezes, sendo que para cada amostra (duodeno e jejuno) foi realizada a medida da altura de 30 vilosidades e a profundidade de 30 criptas.

$\mathrm{O}$ delineamento experimental foi inteiramente casualizado, fatorial $3 \times 2$ (três tratamentos e dois sexos) com três repetições por tratamento, sendo as médias comparadas pelo teste Tukey. Nas avaliações de desempenho, cada baia representou uma repetição e na avaliação histológica cada animal constituiu uma repetição. Para o consumo diário de ração e o consumo diário de água na fase de berçário, foi realizada a correlação geral dos dados. As análises dos dados foram realizadas por intermédio do programa SAEG (UNIVERSIDADE FEDERAL DE VIÇOSA UFV, 1997).

\section{Resultados e Discussão}

As médias das variáveis de desempenho avaliadas nas três fases do experimento e no período total estão apresentadas nas Tabelas 2, 3, 4 e 5. Os valores obtidos nas medidas das vilosidades e criptas do duodeno e do jejuno estão apresentados na Tabela 6 .

Os resultados demonstram que para o DPS os 
Tabela 2 - Efeito da adição de edulcorante na água sobre consumo diário de água (CDA), ganho diário de peso (GDP), consumo diário de ração (CDR) e conversão alimentar (CA) na fase de berçário (10 aos 30 dias)

Table 2 - Effect of drinking water with sweetener on daily water consumption (DWC), average daily gain (ADG), daily feed intake (DFI) and feed:gain ratio (FG) in the nursery phase (from $10^{\text {th }}$ to $30^{\text {rd }}$ day)

\begin{tabular}{lllll}
\hline Fatores & $\mathrm{CDA}(\mathrm{mL})$ & $\mathrm{GDP}(\mathrm{g})$ & $\mathrm{CDR}(\mathrm{g})$ & $\mathrm{CA}$ \\
Factors & $D W C(m L)$ & $A D G(g)$ & $D F I(g)$ & $F G$ \\
\hline
\end{tabular}

Tratamentos

Treatments

\begin{tabular}{lclll}
\hline T1 & $582^{\mathrm{a}}( \pm 72)$ & $92^{\mathrm{a}}( \pm 20)$ & $240^{\mathrm{a}}( \pm 27)$ & $2.71^{\mathrm{a}}( \pm 0,62)$ \\
T2 & $607^{\mathrm{a}}( \pm 135)$ & $96^{\mathrm{a}}( \pm 30)$ & $246^{\mathrm{a}}( \pm 42)$ & $2.69^{\mathrm{a}}( \pm 0,60)$ \\
T3 & $576^{\mathrm{a}}( \pm 96)$ & $99^{\mathrm{a}}( \pm 17)$ & $230^{\mathrm{a}}( \pm 30)$ & $2,34^{\mathrm{a}}( \pm 0,25)$ \\
\hline
\end{tabular}

\section{Sexo}

Sex

\begin{tabular}{lcccc}
$\begin{array}{l}\text { Machos } \\
\text { Males }\end{array}$ & $586 \mathrm{x}( \pm 108)$ & $86 \mathrm{x}( \pm 20)$ & $231 \mathrm{x}( \pm 21)$ & $2.79 \mathrm{x}( \pm 0,61)$ \\
$\begin{array}{l}\text { Fêmeas } \\
\text { Females }\end{array}$ & $591 \mathrm{x}( \pm 95)$ & $105 \mathrm{x}( \pm 21)$ & $246 \mathrm{x}( \pm 40)$ & $2.38 \mathrm{x}( \pm 0,30)$ \\
\hline
\end{tabular}

Médias seguidas de letras diferentes para tratamentos $(a, b)$ ou sexos $(x, y)$, na mesma coluna, diferem $(P<0.05)$ pelo teste Tukey. Means of treatments, within the same column, followed by different letters $(a, b)$ and means of sex $(x, y)$ differ $(P<.05)$ by Tukey test.

tratamentos com e sem edulcorante simultaneamente não determinaram aumento $(\mathrm{P}>0,05)$ na ingestão de água ou no consumo de ração, nem melhora no desempenho na fase de berçário (Tabela 1) ou nas fases subseqüentes ( $\mathrm{P}>0,05)$ (Tabelas 3 e 4). Estas observações discordam de STOCKILL (1990), que, trabalhando com o mesmo edulcorante na mesma dosagem, indicou que a adição de edulcorante na água aumentou consumo de água e ração para leitões desmamados aos 21 dias. $\mathrm{O}$ autor afirmou que, para uma condição clássica de baixo consumo no pós-desmame, o aumento na ingestão de água, pela sua palatabilização, e de ração, como conseqüência, é positivo sobre a digestibilidade e o ganho de peso.

Esta teoria foi contrariada por MAENZ et al. (1993), que não verificaram aumento no consumo de água e ração pelo uso de edulcorante na água ( 2 g de sacarina sódica/litro), mas verificaram que ocorreu relação positiva entre os consumos de água e ração.

Esta mesma observação foi determinada, sendo significativa $(\mathrm{P}<0,01)$ a correlação $(\mathrm{r}=0,78)$ entre os consumos diários de água e ração na fase de berçário.

De acordo com os resultados obtidos por BARTELS et al. (1999), o consumo diário de água para leitões desmamados aos 14 e 21 dias de idade foi semelhante aos valores observados.

Os valores de consumo diário de ração, observados nesta pesquisa foram semelhantes aos indicados pelo NRC (1998) para leitões de mesma faixa de peso utilizados no experimento.

Possivelmente, os modelos de consumo de água propostos por McLEESE et al. (1992) sejam mais adequados para entendimento dos resultados obtidos. Segundo os autores, existem duas formas distintas para explicar o consumo de água no período pósdesmame. Durante a primeira fase, até cinco dias após o desmame, o consumo de água varia independentemente da necessidade fisiológica aparente e não parece estar relacionado com o ganho de peso, o consumo de ração ou a intensidade da diarréia. No segundo período, o consumo de água segue um padrão consistente, relacionando-se positivamente com o ganho de peso e o consumo de ração. Os autores hipotetizam que, durante os primeiros dias após o desmame realizado aos 21 dias de idade, o consumo de água pode ser voluntariamente alto, a ponto de os leitões virem a obter uma sensação de saciedade, limitando o consumo alimentar. Nesse sentido, prova-

Tabela 3 - Efeito da adição de edulcorante na água sobre ganho diário de peso (GDP), consumo diário de ração (CDR) e conversão alimentar (CA) na fase de pré-creche (30 aos 45 dias)

Table 3 - Effect of drinking water with sweetener on average daily gain (ADG), daily feed intake (DFI) and feed:gain ratio $(F G)$ in the pre nursery phase (from $30^{\text {th }}$ to $45^{\text {th }}$ day)

\begin{tabular}{llll}
\hline Fatores & GDP $(\mathrm{g})$ & $\mathrm{CDR}(\mathrm{g})$ & $\mathrm{CA}$ \\
Factor & $A D G(\mathrm{~g})$ & $D F I(g)$ & $F G$ \\
\hline
\end{tabular}

Tratamentos

Treatments

\begin{tabular}{llll}
\hline T1 & $328^{\mathrm{a}}( \pm 30)$ & $473^{\mathrm{a}}( \pm 51)$ & $1.42^{\mathrm{a}}( \pm 0,06)$ \\
T2 & $318^{\mathrm{a}}( \pm 64)$ & $489^{\mathrm{a}}( \pm 86)$ & $1.54^{\mathrm{a}}( \pm 0,09)$ \\
T3 & $337^{\mathrm{a}}( \pm 36)$ & $488^{\mathrm{a}}( \pm 40)$ & $1.45^{\mathrm{a}}( \pm 0,06)$ \\
\hline
\end{tabular}

Sexo

Sex

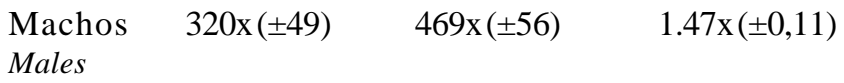

Fêmeas $\quad 336 y( \pm 40) \quad 498 y( \pm 62) \quad 1.46 x( \pm 0,06)$

Females

Médias seguidas de letras diferentes para tratamentos (a,b) ou sexos $(x, y)$, na mesma coluna, diferem $(P<0.05)$ pelo teste de Tukey. Means of treatments, within the same column, followed by different letters $(a, b)$ and means of sex $(x, y)$, differ $(P<.05)$ by Tukey test. 
1774 Rev. bras. zootec.

velmente pela baixa idade do desmame praticado e devido à inabilidade fisiológica dos leitões para consumir água e ração, os primeiros 12 dias poderiam se identificar mais com a primeira fase da teoria, ou supostamente com o hábito de ingerir líquido durante a amamentação. É importante salientar que neste trabalho os resultados foram obtidos com leitões desmamados aos 10 dias de idade.

Para os dados de desempenho foram observadas diferenças significativas $(\mathrm{P}<0.05)$ para o fator sexo (Tabelas 3, 4 e 5), em que as fêmeas apresentaram melhor ganho diário de peso e consumo diário de ração nas fases compreendidas entre 30 e 45 dias e 45 e 62 dias e maior ganho diário de peso no período total do experimento ( 10 a 62 dias). Supõe-se que até a idade de abate, pelo seu desenvolvimento diferenciado, os machos superariam o ganho de peso das fêmeas, contudo, esta observação foi impossibilitada pela conclusão do trabalho aos 62 dias de idade.

Não foi verificada a presença de incidência de diarréia em nenhum dos tratamentos. As ótimas condições de limpeza e desinfecção, temperatura, alimentação, manejo all in all out e o próprio desmame precoce segregado colaboraram para a minimização do problema. As pequenas diferenças no consumo de água e ração entre os tratamentos provavelmente não influenciaram distintamente a maturidade do intestino e nem favoreceram a ocorrência de danos na parede intestinal para qualquer dos grupos experimentais.

Quanto à altura das vilosidades e à profundidade das criptas do duodeno e jejuno médios, avaliado aos 22 dias de idade, os resultados não registraram diferença entre os tratamentos $(\mathrm{P}>0,05)$. A atividade funcional do intestino parece estar diretamente relacionada com a presença do alimento no trato (CERA et al., 1988; KELLY et al., 1991; e MAKKING et al., 1994). Segundo Gall e Chung (1982), citados por CERA et al. (1988), a ingestão de ração tem influência maior na maturação do epitélio do intestino que a própria idade do animal. Entretanto, as hipóteses orientando que a indução do consumo de água, pela sua palatabilização, favoreceria a ingestão de ração, e este alimento, consumido sob maior volume, viria melhorar a estrutura da mucosa, não se confirmaram, permitindo considerar que efetivamente a adição de edulcorante na água não estimulou seu consumo.
Tabela 4 - Efeito da adição de edulcorante na água sobre ganho diário de peso (GDP), consumo diário de ração (CDR) e conversão alimentar $(C A)$ na fase de creche ( 45 aos 62 dias)

Table 4 - Effect of drinking water with sweetener on average daily gain (ADG), daily feed intake (DFI) and feed:gain ratio (FG) in the nursery phase (from $45^{\text {th }}$ to $62^{\text {tnd }}$ day)

\begin{tabular}{lccc}
\hline $\begin{array}{l}\text { Fatores } \\
\text { Factors }\end{array}$ & GDP $(\mathrm{g})$ & $\mathrm{CDR}(\mathrm{g})$ & $\mathrm{CA}$ \\
$\begin{array}{l}\text { Tratamentos } \\
\text { Treatments }\end{array}$ & & & \\
& & & \\
\hline $\mathrm{T} 1$ & $443^{\mathrm{a}}( \pm 79)$ & $727^{\mathrm{a}}( \pm 56)$ & $1,71^{\mathrm{a}}( \pm 0,36)$ \\
$\mathrm{T} 2$ & $444^{\mathrm{a}}( \pm 55)$ & $765^{\mathrm{a}}( \pm 114)$ & $1,71^{\mathrm{a}}( \pm 0,14)$ \\
$\mathrm{T} 3$ & $439^{\mathrm{a}}( \pm 40)$ & $758^{\mathrm{a}}( \pm 55)$ & $1,72^{\mathrm{a}}( \pm 0,13)$ \\
Sexo & & & \\
$\begin{array}{l}\text { Sex } \\
\text { Machos }\end{array}$ & $410 \mathrm{x}( \pm 60)$ & $697 \mathrm{x}( \pm 42)$ & $1,74 \mathrm{x}( \pm 0,29)$ \\
Males & & & \\
Fêmeas & $475 \mathrm{y}( \pm 28)$ & $803 \mathrm{y}( \pm 68)$ & $1,69 \mathrm{x}( \pm 0,13)$ \\
Females & & &
\end{tabular}

Médias seguidas de letras diferentes para tratamentos (a,b) ou sexos $(x, y)$, na mesma coluna, diferem $(P<0,05)$ pelo teste Tukey. Means of treatments, within the same column, followed by different letters $(a, b)$ and means of sex $(x, y)$ differ $(P<.05)$ by Tukey test.
Tabela 5 - Efeito da adição de edulcorante na água sobre o ganho diário de peso (GDP), consumo diário de ração (CDR) e conversão alimentar (CA) no período total - (10 aos 62 dias)

Table 5 - Effect of drinking water with sweetener on average daily gain (ADG), daily feed intake (DFI) and feed: gain (FG) in the total period (from $10^{\text {th }}$ to $62^{\text {nd }}$ day)

\begin{tabular}{llll}
\hline Fatores & GDP $(\mathrm{g})$ & $\mathrm{CDR}(\mathrm{g})$ & $\mathrm{CA}$ \\
Factors & $A D G(\mathrm{~g})$ & $D F I(g)$ & $F G$ \\
\hline
\end{tabular}

Tratamentos

Treatments

\begin{tabular}{llll}
\hline T1 & $275^{\mathrm{a}}( \pm 27)$ & $475^{\mathrm{a}}( \pm 28)$ & $1,71^{\mathrm{a}}( \pm 0,16)$ \\
T2 & $277^{\mathrm{a}}( \pm 43)$ & $491^{\mathrm{a}}( \pm 73)$ & $1,77^{\mathrm{a}}( \pm 0,05)$ \\
T3 & $283^{\mathrm{a}}( \pm 22)$ & $485^{\mathrm{a}}( \pm 35)$ & $1,71^{\mathrm{a}}( \pm 0,05)$
\end{tabular}

Sexo

Sex

Machos $\quad 263 x( \pm 27) \quad 463 \times( \pm 37) \quad 1,76 \times( \pm 0,13)$

Males

Fêmeas $\quad 293 y( \pm 26) \quad 504 x( \pm 49) \quad 1,70 x( \pm 0,05)$

Females

Médias seguidas de letras diferentes para tratamentos (a,b) ou sexos $(x, y)$, na mesma coluna, diferem $(P<0,05)$ pelo teste Tukey. Means of treatments, within the same column, followed by different letters $(a, b)$ and means of sexes $(x, y)$ differ $(P<.05)$ by Tukey test. 
SILVA et al.

Tabela 6 - Efeito da adição de edulcorante na água sobre altura das vilosidades (ALTVILO) e profundidade das criptas (PROCRI) do duodeno e jejuno médios

Table 6 - Effect of drinking water with sweetener on villi height (VILHEIG) and crypt depth (CRYDEP) of the medium part of duodenum and jejunum

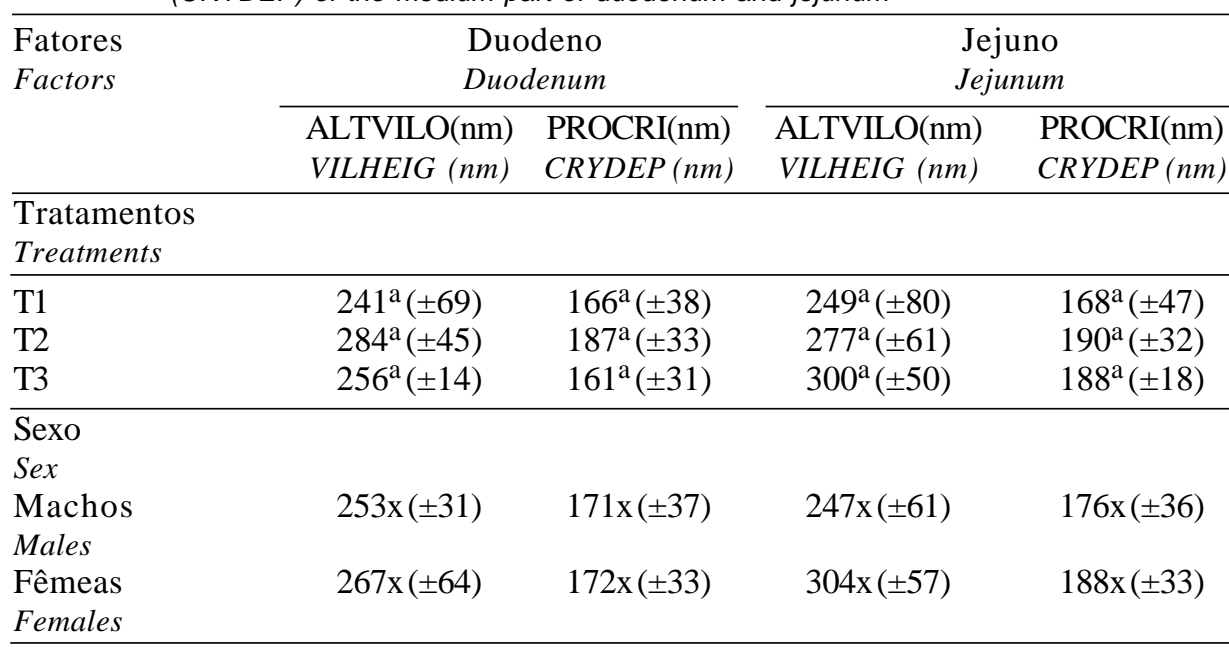

Médias seguidas de letras diferentes para tratamentos $(a, b)$ ou sexos $(x, y)$, na mesma coluna diferem $(P<0,05)$ pelo teste Tukey.

Means of treatments, within the same column, followed by different letters $(a, b)$ and means of sexes $(x, y)$ differ $(P<.05)$ by Tukey test.

\section{Conclusões}

Os desafios fisiológicos do desmame precoce segregado que determinam baixo consumo de água e ração não foram melhorados pelo uso de edulcorante na água nos primeiros 20 dias após o desmame. Os resultados, conseqüentemente, não influenciaram o desempenho e a qualidade da mucosa intestinal e também não determinaram efeitos positivos sobre as fases subseqüentes.

\section{Agradecimento}

À Seghers Hybrid do Brasil, pela gentileza ao permitir a execução do trabalho, cedendo os animais e disponibilizando instalações e funcionários.

\section{Referências Bibliográficas}

BARTELS, H., ÁVILA, V., POPHAL, S. et al. Consumo de água pelos leitões desmamados aos 14 ou aos 21 dias de idade em função do consumo de ração In: CONGRESSO BRASILEIRO DE VETERINÁRIOS ESPECIALISTAS EM SUÍNOS, 9, 1999, Belo Horizonte. Anais... Belo Horizonte: ABRAVES, 1999, p.421-422.

BERTO, D.A. Estudo do ganho de peso compensatório em suínos recebendo no período inicial diferentes tipos de dieta e sistemas de alimentação: Jaboticabal, SP: UNESP, 1993, 131p. Tese (Doutorado em Zootecnia) - Faculdade de Ciências Agrárias e Veterinárias - Universidade Estadual Paulista, 1993.
CERA, K.R., MAHAN, D.C., CROS, R.F. et al. 1988. Effect of age, weaning and postweaning diet on small intestinal growth and jejunal morphology in young swine. J. Anim. Sci., 66(2):574-584

COLE, D.J.A., VARLEY, M.A., HUGHES, P.E. 1975. Studies in sow reproduction.2. The effect of lactation lenght on the subsequent reproduction performance of the sow. Anim. Prod., 20(3):401-406.

DEPREZ, P., DEROOSE, J.P., VANDENHENDE, C. 1987. Liquid versus dry feeding in weaned piglets: the influence on small intestinal morfology. J. Vet. Med. Ser, 34 (6): 254-259.

FREITAS, H.T., FERREIRA, A.S., DONZELE, J.L. et al. 1997. Manejo para desmame de leitões aos 21 dias de idade. R. Bras. Zootec., 26(4):753-758.

HEIMIG, D. 1996. Why $78 \%$ of feeds choose liquid system. Pigs, 12(6):9.

KELLY, D., SMITH, J. A., MACRAKEN, K. J. 1991. Digestive development of the early weaned pig. 2. Effect of level of food intake on digestive enzyme activity during the immediate post weaning period. Br. J. Nutr., 65(1):181-188.

MADEC, F., JOSSE, J., CHANTAL, A. 1989. Evaluation dúne methode multifactorielle dans Lánalyse des troubles digestifs du savage. J. Rech. Porcine, 14:379-386.

MAENZ, D.D., PATIENCE, J.F., WOLYNETZ, M.S. 1993. Effect of water on the performance of newly weaned pigs offered medicated and unmedicated feed. Can. J. Anim. Sci., 73(3):669-672.

MAKKING, C.A., NEGULESCU, G.P., GUIXIN, Q. et al 1994. Effect of dietary protein source on feed intake, growth, pancreatic enzyme activities and jejunal morphology in newly weaned piglets. Br. J. Nutr., 72(3):353-368.

McDONALD, P., EDWARDS, R.A., GREENHALGH, J.F.D 1987. Voluntary intake of food. In: Animal nutriction. New York: Longham Inc. 4.ed. p.375-387.

McLEESE, J.M., TREMBLAY, M.L., PATIENCE, J.F. et al 1992. Water intake patterns in the weaning pig: effect of water 
1776 Rev. bras. zootec.

quality, antibiotcs and probiotics. Anim. Prod., 54:135-142.

MORES, N. Diarréia pós-desmame em leitões In: MINISIMPÓSIO DO COLÉGIO BRASILEIRO DE NUTRIÇÃO ANIMAL, 10, 1993, Valinhos. Anais...Campinas: CBNA, 1993, p.101-115.

PASSOS, H.S. Nutrição e meio ambiente para leitões em sistema e produção com desmame precoce segregado. In: CONGRESSO BRASILEIRO DE VETERINÁRIOS ESPECIALISTAS EM SUÍNOS, 8, 1997, Foz do Iguaçu. Anais... Foz do Iguaçu: ABRAVES, 1997, p.41-54.

PEKAS, J.C. 1991. Digestion and absortion capacity and their development. In: MILLER, E.R., ULLREY, D.E., LEWIS, A.J. (Eds.) Swine nutrition. Stonehan: Butterworth-Heineman. 1.ed. p.37-73.

STOCKILL, P. 1990. Water: whey it should not be the neglected nutrient for pigs. Feed Int., 11(10):10-18.

UNIVERSIDADE FEDERAL DE VIÇOSA - UFV. 1997. SAEG - Sistema de análises estatísticas e genéticas. Versão 7.1. Viçosa, MG. 150p. (Manual do usuário)
VIEIRA, R.P., VIEIRA, H.P., MADEC, F. 1989. Aplicação da análise multidimensional na prevenção da patologia digestiva do desmame em suinocultura intensiva. Rev. Port. Ciências Veterinárias, 84(492):229-241.

WHITTEMORE, C.T. 1998. Requeriments for water, minerals and vitamins. In: WHITTEMORE, C.T. (Ed.). The science and practice of pig production. Boston: Blackwell Science. 2.ed. p.356-365.

Recebido em: 10/11/99

Aceito em: 19/04/00 